\title{
Microfilariae in Breast Aspirates in 45 Years Old Female: A Rare Case Report
}

\author{
Mahendra Singh $^{1}$, Anveksha Sachan ${ }^{2 *}$, Anita Omhare ${ }^{3}$, Swetlana Sachan $^{2}$ \\ ${ }^{1}$ Professor \& Head, Department of Pathology GSVM Medical College, Kanpur, India \\ ${ }^{2} J$ unior Resident III, Department of Pathology GSVM Medical College, Kanpur, India \\ ${ }^{3}$ Assistant Professor, Department of Pathology GSVM Medical College, Kanpur, India
}

*Address for Correspondence: Dr. Anveksha Sachan, Junior Resident III, Department of Pathology, GSVM Medical College, Kanpur, India

E-mail: riyasachan12@gmail.com

Received: 15 Dec 2018/ Revised: 17 Mar 2019/ Accepted: 18 Jun 2019

\begin{abstract}
Background: Filariasis is a chronic disabling parasitic disease. It is more prevalent in the coastal areas and river banks of India. Breast is a very uncommon site of the filarial lesion.

Methods: We have reported a case of 45 years old female with chief complaints of painless increasing breast mass on the left outer quadrant. There was no history of fever, weight loss, and anorexia as nipple discharge. On palpation swelling was large, mobile, soft cystic and diffuse USG revealed a hypoechoic lesion on the outer quadrant of the left breast. The diagnosis was confirmed by fine needle aspiration cytology of the breast aspirate.

Results: A 45 years old female patient presents with a painless increasing breast mass. FNAC was performed and findings were suggestive of parasitic cyst in breast microfilaria.

Conclusions: Absence of microfilaria in peripheral blood does not rule out filariasis. Filarial Breast Nodule was rare and it often mimics a neoplastic breast lesion so, FNAC was a very effective diagnostic tool in the diagnosis of filarial breast lesion.
\end{abstract}

Key-words: Breast, Filariasis, FNAC, Microfilaria, Neoplastic breast lesion, Peripheral blood

\section{INTRODUCTION}

Filariasis is a chronic disabling parasitic disease, prevalent in South Asia and Africa ${ }^{[1,2]}$. In India, filarial infections are commonly caused by two closely related nematodes i.e. Wuchereria bancrofti and Brugia malayi $[1,3]$. It is more prevalent in the coastal areas and river banks of India ${ }^{[2,4]}$. The disease follows a chronic course and mainly affects the lymphatics of lower limbs, spermatic cord, and epididymis, retroperitoneal lymphatics etc ${ }^{[1]}$. Breast is a very uncommon site of the filarial lesion ${ }^{[4]}$. The conventional mode of diagnosed is by demonstration of microfilaria in the peripheral blood smear ${ }^{[2-6]}$. We are presenting a very uncommon case of filariasis occuring in breast.

How to cite this article

Singh M, Sachan A, Omhare A, Sachan S. Microfilariae in Breast Aspirates in 45 Years Old Female: A Rare Case Report. SSR Inst. Int. J. Life Sci., 2019; 5(4): 2369-2371.

\begin{tabular}{|c|c|}
\hline & Access this article online \\
& https://iijls.com/
\end{tabular}

CASE REPORT- A 45 years old female came with the history of painless increasing breast mass on left outer quadrant. There was absence of fever, weight-loss, anorexia and nipple discharge. On examination, the patient was averagely built and on clinical examination of breast revealed a large mobile swelling which was soft, cystic and diffuse.

A

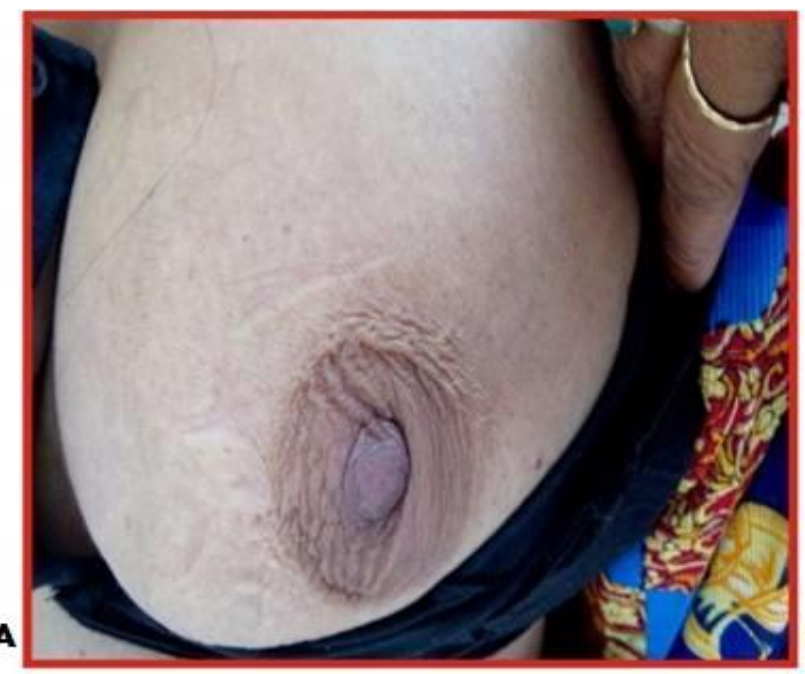




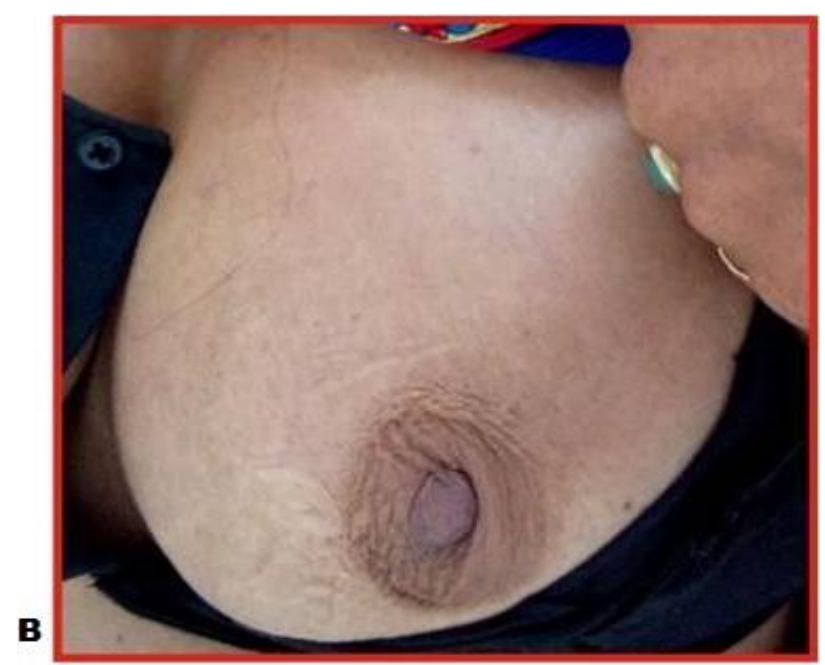

Fig. 1 (1A,B): Depicts painless, soft breast mass on left quter Quadrant

The approximate measurement was $8 \times 7 \mathrm{~cm}$. The outer skin was normal. No nipple retraction was observed. No axillary lymph nodes were palpable on the same side and opposite side of the involved breast. Routine hematological and biochemical parameters were within normal limits. Ultrasonography revealed a hypoechoic lesion on the outer quadrant of the left breast.

Microscopic Examination- The stained smears were cellular showing dense inflammatory cells infiltrate comprising of macrophages, lymphocytes, neutrophils along with clusters of ductal epithelial cells. In addition to this numerous large thread like structuresmicrofilariae were also seen. Few degenerated coiled forms of larvae were also observed in examined smears. The findings were suggestive of parasitic cyst in breast microfilaria.

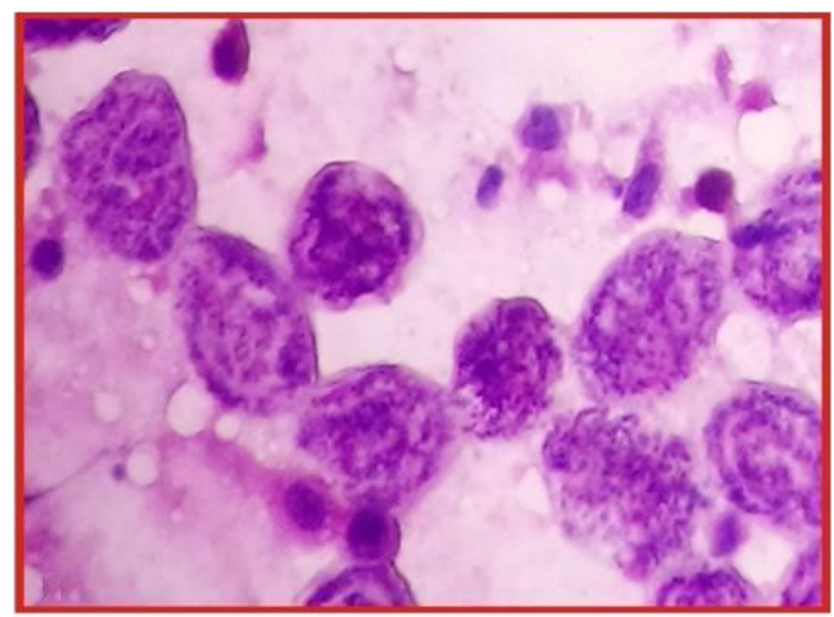

Fig. 2: 40x magnification depicts multiple degenerated coiled forms of microfilariae

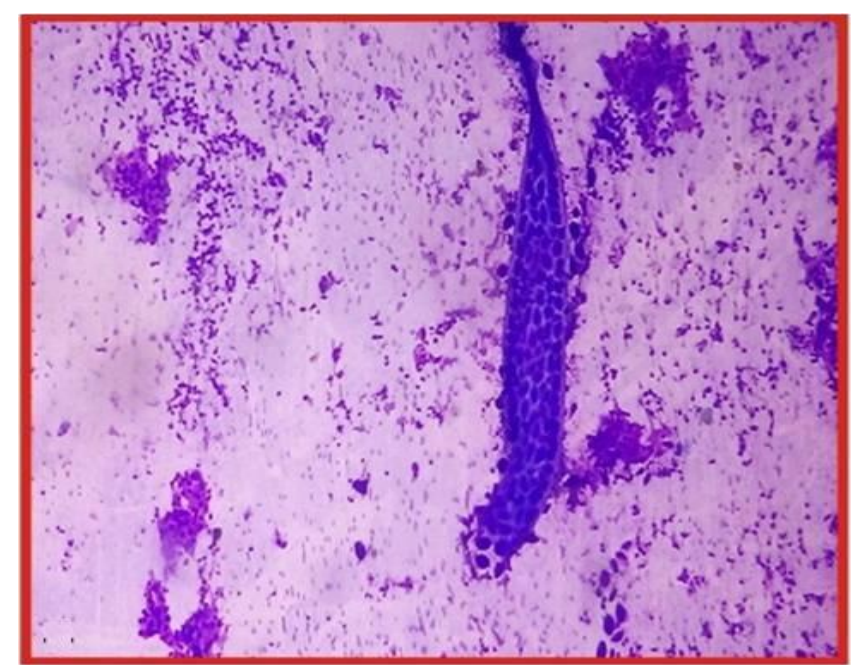

Fig. 3: On scanner-microfilaria along with Ductal epithelial cells and inflammatory cells

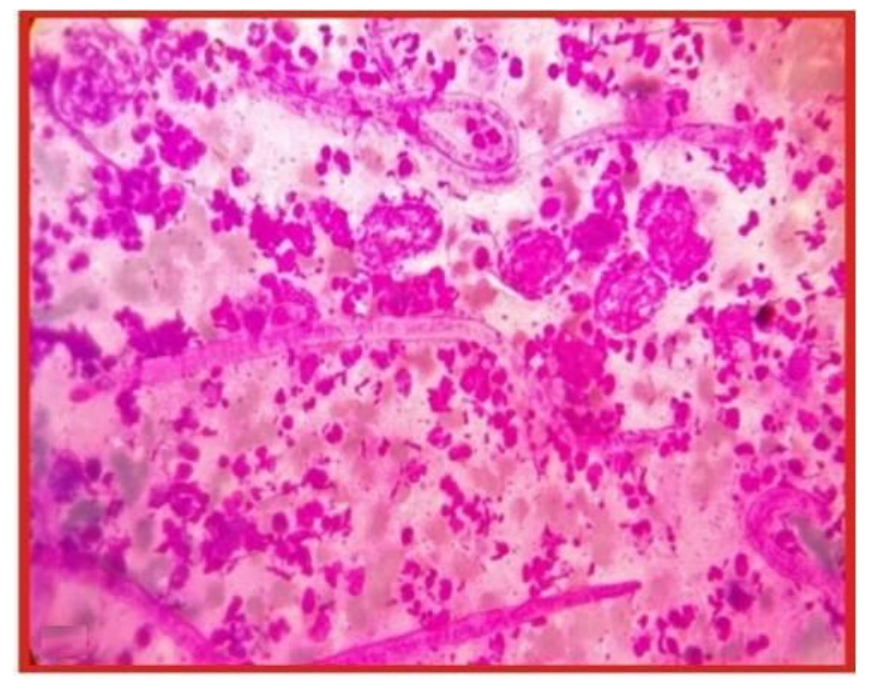

Fig. 4: 10x magnification depicts multiple sheathed microfilariae

\section{DISCUSSION}

The highest number of cases of filariasis occurs in India where more than $\mathbf{3 0 0}$ millions of people live in endemic areas ${ }^{[7]}$. In endemic areas like U.P., people get infected with this disease early in life and majority of these infected people are asymptomatic in endemic areas ${ }^{[5]}$. Most of the cases were caused by $W$. bancrofti and $B$. malayi ${ }^{[2,3]}$.

Breast is a very uncommon location for filariasis and very less number of cases has been reported in English literature ${ }^{[1-3]}$. A filarial breast lesions present with a nodular firm mass often mimic neoplastic lesions in clinical examination ${ }^{[1]}$. FNAC was a very well-established, easily available, very much simple and cost-effective method to evaluate neoplastic and non-neoplastic lesions occurring in breast ${ }^{[2]}$. Filarial breast lump may be 
due to filarial lymphangitis, which leads to chronic inflammation and fibrosis due to disrupted lymphatic vessels ${ }^{[2]}$. Diagnosis of filarial lesions largely depends on the demonstration of microfilaria larval form in the peripheral blood, body fluids and tissue aspirates ${ }^{[8]}$. The identification of species is very often problematic in the adult worm, but it is quite possible on the basis of microfilarial structure and morphology ${ }^{[1,4,9]}$. The Main differentiating points include- length (which was larger in W. bancrofti), secondary kinking (which was found in $B$. malayi) in comparison to smooth curves (in $W$. bancrofti), tale tip (free of nuclei in $W$. bancrofti but two discrete nuclei observed in $B$. malayi) ${ }^{[1,4,9]}$.

It is believed that in the early allergic stage of the disease, microfilaria do not appear in peripheral blood and so diagnosis largely depends on the lymph nodeFNAC or biopsy which is present adjacent to the area of lymphangitis and/or by few immunologic tests ${ }^{[10]}$. Imaging studies of the lymph node are of very little importance in the diagnosis of microfilaria as the findings were not very much conclusive ${ }^{[11]}$.

\section{CONCLUSIONS}

Absence of microfilaria in peripheral blood does not rule out filariasis. Histopathology may not always show microfilaria or adult worm. Therefore, FNAC is recommended as an invaluable tool in the diagnosis of lymphatic filariasis. Filarial breast nodule is very uncommon, and it often mimics a neoplastic breast lesion. FNAC was a very effective diagnostic tool in the diagnosis of filarial breast lesion and it helps to avoid unnecessary surgical procedures.

Lymphatic filariasis should always be considered as a differential diagnosis for nodular all the nodular breast lesions, which are of short duration, particularly in countries like India, where filariasis is an endemic disease.

\section{ACKNOWLEDGEMENTS}

All authors were thankful to the Department of pathology, GSVM Medical College Kanpur, India for help in writing this rare case report.

\section{CONTRIBUTION OF AUTHORS}

Research concept- Dr. Anveksha Sachan

Research design- Dr. Anita Omhare

Supervision- Dr. Anita Omhare

Materials- Dr. Anveksha Sachan

Data collection- Dr. Swetlana Sachan

Data analysis and interpretation- Dr. Anita Omhare

Literature search- Dr. Mahendra Singh

Writing article- Dr. Mahendra Singh

Critical review- Dr. Anveksha Sachan

Article editing- Dr. Swetlana Sachan

Final approval- Dr. Mahendra Singh

\section{REFERENCES}

[1] Kaur R, Philip KJ, Masih K, Kapoor R, Johnny C. Filariasis of the breast mimicking inflammatory Carcinoma. Lab Med., 2009; 40(11): 683-85.

[2] Dayal A, Selvaraju K. Filariasis of the Breast. Cent. Surg., 2010; pp. 1-5.

[3] Khan R, Harris SH, Maheshwari V. Filarial breast mouse J. Coll. Physicians Surg. Pak, 2011; 21(8): 513.

[4] Bhardwaj S, Mahajan D, Attri MR. Filariasis of the breast. JK Sci., 2007; 9: 98-99.

[5] Mitra SK, Mishra RK, Verma P. Cytological diagnosis of microfilariae in filariasis endemic areas of Eastern Uttar Pradesh. J. Cytol., 2009; 26(1): 11-14.

[6] Hippargi SB, Kittur SK, Yelikar BR. Filariasis of the breast, diagnosed by Fine Needle aspiration cytology. J. Cytol., 2007; 24: 103-04.

[7] Paniker Jayaram CJ. $6^{\text {th }}$ ed. Jaypee brothers. Paniker's Text book of Medical Parasitology pp. 197, Chapter 21, Filarial worms, 2011.

[8] Pal S, Bose K. Microfilaria in fine needle aspiration cytology of breast lump: An unusual finding. J. Health Spec., 2015: 3: 235-37.

[9] Chatterjee KD. Phylum nemathelminthes, class nematoda In: Parasitology (Protozoolagy and Helminthology). $13^{\text {th }}$ edition. Kolkata: Chatterjee medical publishers; 2009; pp. 199-258.

[10]Chatterjee KD, Phylum Nemathelminthes. In K.D. Chatterjee (ed), Parasitology $12^{\text {th }}$ edition. Calcutta, Chatterjee Medical Publishers, 1980; 188-98.

[11]Basu A, Sistla SC, Verma SK, Jagdish S. Lymphadenovarix in the axilla: an unusual presentation of filariasis. Filaria J., 2006; 5: 9.

\section{Open Access Policy:}

Authors/Contributors are responsible for originality, contents, correct references, and ethical issues. SSR-IIJLS publishes all articles under Creative Commons Attribution- Non-Commercial 4.0 International License (CC BY-NC). https://creativecommons.org/licenses/by-nc/4.0/legalcode (c) (1) (8) 